parts to the extent of a quarter of an inch, and like fibro-cartilage.

Dislocation of the Spine.-On the 16th February, 1848, Mr. Dunn presented, what he considered to be, a dislocation of the spine, between the last cervical and first dorsal vertebræ, in a young man aged 22 , who was canght by the smock-frock, and dragged into a thrashing mill. It seemed to be a laceration of the intervertebral substance, but there did not appear to be any fracture of the articulatory surfaces. Mr. Dunn considered this to be a case of pure dislocation of the spine, though this is denied by most writers.

On the same evening Mr. Shoreland related the case of a soldier, who in a state of partial intoxication slipped from a verandah, ten feet high, but caught by his hands when falling, which gave a jerk to the spine, and fractured the fourth dorsal vertebra. He was taken to the hospital, where he remained till next morning without shewing any signs of paralysis, and he was not minutely examined, it being supposed at the time that it was merely a contusion from the fall. Whilst sitting up in bed and taking his breakfast the next morning, he was observed to have fallen forwards, and on the orderly raising him up, he was found quite dead. On inspection after death the spine was found dislocated, with fracture of the bone. Sitting-up produced a displacement, and fatal pressure on the cord was the consequence.

Operation for Cicatrix.-On the 19th of April, 1848, Mr. May presented Charlotte Taylor, a hospital patient, whom he introduced to the Society on a former occasion, and who had undergone the operation of a section of the skin under the chin, which was drawn down by the cicatrix of an old burn. The girl happening to be in town, called to show herself, and prove the great and satisfactory results of the operation, by which the deformity is nearly abliterated, and there is no appearrance of a return of the contraction.

I have now, gentlemen, completed the history of the transactions of our Society during the past year, and though we cannot boast of much that is novel or striking in what has been brought forward, yet, we may safely say that there has been much that is practical and useful.

Let us not relax for one moment in our efforts to advance the standard, and promote the usefulness of our profession. If we can add but one mite to the treasury of medical knowledge, we shall have performed a duty to our fellow creatures, and created a feeling of satisfaction in our own consciences. It is by the interchange of ideas,-by the aggregation and association of talent, that we may hope to increase our professional knowledge, and societies like ours are well calculated to effect this object.

Before concluding this address, I would express the thanks of the Society to Mr. Dunn, for his kindness in undertaking the care of the museum.

I thank you, gentlemen, for your kind and patient attention to this prolonged, and I fear, somewhat tedious address.

\section{OBSERVATIONS ON CHOLERA.}

\section{By Chardes Cowan, M.D., Physician to the Royal} Berkshire Hospital.

(Read before the Provincial Medical and Surgical Associa. tion, at the Anniversary Meeting, held at Bath, August 16th and 17 th, 1848.)

"'At the present moment, the following non-professional experience on the all-engrossing subject of cholera, drawn up by Lieutenant General Welsh, of the Madras army, a true Christian philanthropist, and a sound observer, will not, I feel sure, be unacceptable. Such evidence has, at all events, the advantage of being free from professional bias, while it essentially confirms the conclusions of the majority of medical writers, as to the cause, progress, treatment, and non-contagious character, of this terrible disease. It has also the strong recommendation that the means so diligently employed were attended wilh more than ordinary success. To the best of General Welsh's recollection, he thinks that the deaths did not exceed five or six in a lundred, while many medical men were losing from a fourth to one half of their cases. He attributes the favourable result in his own practice to the power of wholly devoting himself and servants to the prompt application of the remedies, and to never abandoning their vigorous employment until life was extinct; and under circumstances similar to those which now threaten us, we must be indebted to reported results more than to theory, for our therapeutics.

Notwithstanding all that has been written, (and it is legion,) we are wholly ignorant of the essential cause of cholera, and our treatment must therefore, necessarily, to a certain extent, be empirical. On the other hand, it is impossible to doubt, that means of the most opposite class have, in numerous instances, proved efficient, and out of the vast mass of information now accumulated, each practitioner must select those processes of cure most congenial to his judgment, and most sanctioned by success. Hence the importance of collecting the experience of individual observers, that some approach to soundness of inference may be secured, from the very extent, if not from the accuracy, of the materials.

The neutralizing power of large numbers over minor discrepancies is well-known, and, on a similar principle, from vague, though widely concurrent, testimony, many valuable practical indications may be deduced. This idea is now receiving a very apt illustration in the pages of our useful and greatly improved Journal, on the important question of the treatment of burns, and we think a similar concentration of experience on the therapeutics of cholera, would equally elicit some interesting results, and greatly tend to settle the general line of practice most prudent to adopt.

Judging from the long ages which have elapsed, there is but little reason to anticipate that we shall ever become familiar with any of the specific causes of 
epidemic diseases, but our increasing acquaintance with the conditions favourable to their production, extension, and intensity, fully justifies the assertion, that by wise sanitary arrangements, their frequency, prevalence, and fatality, may be materially curtailed. It is, therefore, to Sanitary Reform rather than to medical interference, that the attention of Government and of the profession, should be chiefly directed, and until vast changes are accomplished in our present most imperfect and injurious social conditions, the best-directed efforts of medical science will fail to preserve the population of this or any other country from being largely victimised by epidemic visitations.

No more striking exemplification can be afforded of man's short-sightedness, and of the difficulty in carrying out the most self-evident improvements, whenever any present sacrifice is to be made, prejudices relinquished, or old habits overcome, than the coldness and opposition experienced by those who are so meritoriously deroting themselves to this truly practical and important question; and from such an experience how easy is it to understand the obstacles which have ever impeded the progress of a purer speculative truth, where facts of such a purely sensual and self-evident character are greeted with so unwilling-so imperfect a response! But to return to our author:-

"The first appearance of this dire and inexplicable pestilence, says General Welsh, took place in the year 1817, when it broke out suddenly in Bengal, and made particular havoc in the town of Calcutta, and among the shipping in the river Hoogly; from thence, apparently travelling in a western direction, over an immense tract of country, with high mountains, and other apparent obstacles intervening, it made its way to Bombay, and then down the whole Malabar coast. It afterwards appeared to reascend the mountainous Ghauts, which separate the sea-coast from the interior of the Peninsula, passed tbrough the Mysore into the Carnatic, where its ravages spread terror and dismay in every direction; visiting, in the whole route, the lowest grounds, with the keenest severity, but generally losing its force at each place where it rested, after a few weeks continuance. In some places it completely thinned the inhabitants, but its attacks were mostly confined to travellers and poor people, living in low, damp, and swampy spots; and in many cases; an immediate removal from such situations to high ground, even in the very neighbourhood, has arrested the spreading evil, and even restored the afflicted individual to health.

"In the Jears 1819 and 1820 , it appeared to be at its height, and generally spread all over India ; and the strongest proof of its being confined to low ground is the fact, that in the Mysore country, while thousands were attacked and perished at Seringapatam, (a low island formed by the junction of two rivers,) it never reached Bangalore, the largest and highest military cantonment in the Peninsula; and in the same degree it was felt at Calcutta, and on the Malabar coast, while the higher civil and military stations of Tellicherry, Cannanore, and Mangalore, were comparatively free.

"I do not assert a total exemption in any place, because the seeds of the disease may be sown at a distance, and only break out on arriving at a bealthy stution, and possibly then spreading by contagion; but after raging for two or three years, and in too many instances baffling all the attention of man, its virulence gradually abated, and latterly only extended to corps and bodies of men on the march, who were naturally more exposed to the night air, and subject to the baneful influence of every kind of malaria.

"Symptoms.-The symptoms of this disease are so various, and in many cases so resembling others of a different nature, that it defies all regular description. The most common are as follows :-

"It commences with a degree of stupor, diarrhœa, and general lassitude, and a painful sensation of heat and fulness in the stomach and chest. Vomiting follows, at first producing undigested food, afterwards an occasional discharge, more or less copious, of watery, whitish, or discoloured and fotid liquid, which passes in many cases involuntarily, both up and down; an immediate prostration of strength; a pulse rapidly decreasing until it is entirely lost; a total suppression of urine; the extremities becoming cold and covered with a clammy moisture; great thirst and restlessness, with violent contortions in some, and lethargic inanimation in others; the eyes glazed and sunk in the head; skin shrivelled, and in short, the whole appearance of a bealthy youth of 17 or 18 turned suddenly to that of decrepid old age. This is the most common kind, and it is the easiest cured if taken in_time.

c. There is another in which few, if any evacuations take place, but in addition to the early symptoms of the first, the whole frame suffers a rigid contraction of the muscles, with the eyes as it were starting out of their sockets. But the worst form of all, within my observation, is one in which the patient rapidly sinks without a struggle, and if not timely relieved, expires in the course of two or three hours. The termination of the first is usually within twenty-four hours; that of the second in a half or even a fourth of that time; but in all, the remedies must take effect in a few hours, or they are almost invariably hopeless, though they should never be relaxed or abandoned, till life is positively extinct.

"Causes.-The predisposing causes in the human frame, are generally considered to be a paucity or total absence of bile in the stomach, a derangement of the digestive organs, and poverty of blood, arising most likely from impure air, and unwholesome aliment; but $I$ have also found, in many cases, a subsequent indication of a very different cause, and wherever it has occurred, the patient has by diligent perseverance in the means, under God's blessing, invariably recovered.

"It has generally taken place after all the alarming symptoms of the first form have been exhibited, and the treatment apparently ineffectual, when suddenly a large worm, eight or ten inches long, has been discharged by the mouth, and the patient, overcome with the exertion, has sunk into a death-like stupor. Then, and then only, have I administered nourishing cordials, particularly port-wine, of which a wine-glass was given every balf-hour, until returning animation proclaimed a happy rescue from the jaws of death. The circumstance now mentioned was not commonly known among the medical men with whom I was acquainted in India, which may easily be accounted for, when it is 
considered that no surgeon there could give his entire and undivided time to any patient, or even to two or three. Whereas, in the years 1818-19 and 20, I happened to be comparatively idle, holding an independent staffsituation, and having my whole family in England, I was consequently enabled to give my whole time and attention, day and night, to such poor natives as were taken ill in my immediate neighbourhood, and with my own servants to assist me, could watch the whole progress of the disease, and observe the effects of every application in each of my patients.

"My practice and experience were chiefly among the lower orders on the Malabar coast, mostly at Calicut in those years, and afterwards among small parties of native troops and followers attendant on myself and family. In other parts of the Peninsula there were always experienced medical men present, with whom I would not, of course, presume to interfere.

"Contagion.-At that time no one ever suspected that the disorder was infectious, and fortunate indeed was this for thousands, whose lives were preserved through the willing attendance of their family and friends, and who would otherwise have been inhumanly abandoned to their fate; and notwithstanding the now too-generally received impression, that it is contagious, I still feel inclined to question that opinion, unless where the predisposing causes exist.

"Though an invalid, subject to constant attacks of bile, liver, and indigestion, I have attended many patients at once, both in my own house, and in the lowest and most miserable situations, where it has been raging all around us with fatal effect, yet neither myself, nor any of my servants (about ten in number,) who all cheerfully assisted me, ever had a symptom of the disease; and if $I$ might venture to explain the idea $I$ have formed of the progress of this almost universal scourge-this severe visitation of God, I would call it an epidemic, contained in a quantity of impure miasm floating in the air, and more particularly attracted by low, damp, and fil hy spots, in which a certain degree of miasm may always be supposed to reside.

"Treatment.-If the patient is young or middle aged, vigorous and sanguineous, and no medical aid at hand, a vein should be opened, and twenty or thirty ounces of blood taken, to insure which, the blood in most cases becoming dark and stagnant, it is necessary, after the incision, to rub the arm, and put the feet in hot water, (if a hot bath cannot be procured,) as well as to administer and continue warm antispasmodic draughts, with warm frictions, and applying hot 'surtostances to the body and extremities, of which a very simple and efficacious one is sand, heated in a pan over a fire, and put into small linen bags or old stockings, and kept in contact with the hands and feet, stomach and spine; no quantity of liquid to be given, and nothing cold, particularly water, for which the patient usually has an incessant craving. Warm gruel is, perhaps, the best vehicle for everything.

"Vatious stimulating medicines have been tried by different people, with pretty nearly the same effect; and $I$ have at times, when travelling, and nothing else was at hand, given essence of ginger, brandy, laudanum, peppermint, \&c.; but where all the articles could be procured, I would recommend, (always and only in the absence of medical aid,) in addition to an immeidiate warm bath, half an ounce of the following mixture, more or less frequently, in a little warm lgruel:Opium, dr. j.; Camphor, dr.j.; Ginger, dr.j. Cardamoms, dr. j. ; Capsicums, dr. iss. ; Arrack or Brandy, oz. viij. M. To be infused for seven days.

"If this be not prepared, half a glass of brandy, with forty or sixty drops of laudanum, and twenty or thirty drops of essence of peppermint, may be substituted; or twenty grains of camphor, or from a tea to a dessertspoonful of essence of ginger, either dose to be repeated every half hour or oftener, if not retained on the siomach, till a favourable change becomes visible. Warm enemas have proved beneficial, especially when the retching continued aad the draughts were returned, and in one instance succeeded, when all hopes by other means were at an end. Calonel in large doses was used hy the faculty in India, and succesfully I believe; but I never had an opportunity of trying $i$, because there was not any to be purchased during the first two or three years of the pestilence.

"Signs of Cure.-The first indications of amendment, where the blood has been originally congealed, are,-its becoming limpid, and fowing freely, a return of the pulse, of warmth in the body, of softness and pliability in the skin, and falling into an easy slumber; but the most certain prognostic of a cure is the free passage of urine. A sleep of some hours succeeds, and the patient generally awakens to convalescence; I say generally, for in the course of $\mathrm{my}$ experience some few apparently relieved fell into a quiet slumber, from which they only awoke to breathe their last sigh, or expired without awaking at all.

"After-Treatment.-As soon as the first attack has been got over, a large dose of castor oil should be given, or a strong bolus of calomel and opium, and after its operation, if no fever should intervene, the patient should be warmly clad, and nourished with cordials and plain wholesome food, in small quantities, but particularly avoid all fruit, regetables, or cold draughts, for some considerable time, as every relapse is attended with the utmost danger."

In conclusion, our author remarks, "as nothing is so conducive to illness, particularly the one in question, as terror or alarm, I would earnestly recommend to all my fellow-creatures to place a cheerful reliance on the all-sufficient protection of a long suffering and ever gracious Redeemer, and to be prepared, by a life of faith and consequent usefulness, for whatever may befal them."

The preceding observations, though couched in nonprofessional language, embrace within a brief compass the chief points in the experience of our most practical writers, and are highly creditable to the zeal, the jutelligence, and the philanthropy of the writer. They strongly point out the protective value of sanitary arrangements, -the greater prevalence and intensity of cholera in undrained, low, and damp situations,- the striking exemption of higher localities, - and the great advantages of removing the sick from the scene of infection.

On these main indications, confirmed as they are by widely convergent testimony, should all our prophylactic measures be based ; and it is deeply to be regretted, that the army of selfish impediments which hare hitherto obstructed the progress of sanitary measures, 
must in the present instance render impossible, more than very imperfect and almost futile attenpts at their accomplishment, arrived as we now are, at the eve of a closely impending visitation.

It is not by quarantine regulations, -it is not by boards of health,-it is not by printed circulars of directions,-it is not by skilful mediciual combinations, that we shall ever materially control the spread or the mortality of this or of any other epidemic; but by fundamental social improvements, which long years alone can effect, and which a truly enlightened and philanthropic government, backed by an intelligent population, can alone carry out.

Had our noble profession, on all matters relating to the public health, that prominency assigned to it to which it is so justly entitled, the chariot-wheels of Sanitary Reform wonld not have lingered as they have done; and to the untiring energies, generous efforts, and scientific acquirements of many among our ranks, are we now indebted for those dawning hopes of future improvement, which we may, perhaps, at length, justly venture to entertain.

On the much-contested and important question of the contagion of cholera, the conclusions of the writer are also consonant with those of the majority of practical observers; and during my own close contact with the disease in Paris, for about three months, in 1832, where it prevailed more intensely than in any other capital of Europe, the whole of my experience was decidedly adverse to the idea of contagion. I would not assert that cholera is never contagious, nor advise unnecessary communications with the sick ; butjudging from what $I$ personally observed, that the disease is very rarely, if ever, so communicated, and that the epidemic influence is all-important for its propagation, I cannot for a moment doubt.

As a confirmatory instance I may mention, that the great corn granary of Paris was converted into a temporary cholera hospital of one thousand beds, and to this a staff of twenty physicians and sixty students was attached. Now, though the whole of our time was deroted to the infected, taking our meals and sleeping two nights a week in the hospital, not to mention almost numberless post-mortem investigations, I do not recollect that a single medical officer, student, or even nutre, caught the disease. My own heaith was remarkíbly good; and it was not till having relinquished all active exertions, and at the very close of the epidemic, that I was personally a snfferer.

Of the fatal influence of fear and despondency I witnessed very striking examples in two newly appointed hospital physicians ; and of the powerful agency of hope, I wàs myself an instance; for being lifted on the outside of a diligence, to return to England, under circumstances considered most hazardous if not hopeless by my friends, a ride of a few hours, under God's blewing restored me to comparative health.
With reference to treatment I have nothing to communicate founded upon the results of my own practice, nor have I the time on the present occasion, to give, as $I$ intended, a digest of the many plans which have been recently recommended. But as a large proporportion of the practitioners of this country are in similar circumstances to my own, viz., pensioners upon the experience of others, I may mention, that the result of my gleanings from the various treatments that are recorded, is in favour of the combined employment of those measures to which active efficiency can be fairly attributed, being guided in their individual application by the general principles of medical art.

On the great importance of attending to the early symptoms, and especially to the initiatory diarrhœa, all observers strongly and unitedly insist, that against this stage of the disease, too much care and promptness cannot be employed. In the early period of collapse, in robust plethoric individuals, there is much evidence in favour of bleeding. A stimulating emetic when the first rowiting is imperfect, followed by a full dose of calomel and opinm, more or less frequently repeated with the unlimited use of effervescing salines, or in their absence, of cold water, with stimulants internally and externally, especially the latter, in proportion to the collapse, and regulated by the feelings of the patient, form the leading features of the plan I should feel most disposed to adopt, while I doubt not many cases would occur, where nothing should at first be altempted but the most energetic application of warmil and stimulants.

As to a host of smaller remedies, to which great vittues are attached, their employment should nerer interfere with the more rational and intelligible indications, and $I$ believe that our success in the management of this most urgent and formidable disease, will be proportionate to our little confidence in specifics, and our steadily carrying out, independently of name or theory, the leading principles of our art. In addition to the above suggestions, I would remark, that it is highly worthy of experiment how far packing with blankets in a cold or warm wet sheet, at the commencement of collapse, or even after its establishment, would tend to induce reaction, and allay the cramps and restlessness more rapidly than any other plan, while under circumstances where this is opposed, the spiritvapour, and hot-air bath, would most effectually contribute to the same result. It is also a point of some practical value to consider whether, in many cases, the effervescing salines, or cold water, might not be replaced by unlimited drinks of beef-tea, salted or spiced, cold or warm, as preferred, containing, as it does, most of the elements so quickly drained off by the diarrhœa.

Before concluding this very brief outline of our subject we would merely observe, that the main and immediate indications of treatment appear to be the 
shortening of the duration, and the diminishing of the intensity of the collapse, restraining the discharges, and supplying at the same time the elements which are so rapidly remored. Warmth, stimulants, and diluents, we therefore regard as the leading therapeutical agents, and should classify opium, calomel, acetate of lead, petroleum, croton oil, \&c., as among the more or less useful adjurants. It cannot be too often repeated, that the success of all rational treatment will be in proportion to its prompt and early application.

Of the essential cause, and true nature of cholera, we shall not attempt their elucidation, satisfied that nothing is easier or more delusive than to mould our facts to our fancied explanations, and to multiply words without knowledge.

We again admit ourselves to be amongst the number of the wholly ignorant on both these fundamental points, and as yet to bave thanklessly rejected all efforts at enlightenment. What the future may develop it is not in our power to divine, but judging from the past and the present, no one similarly constituted to the writer will feel surprise, if his expectations are not very sanguine.

[The following letter has been communicated by Dr. Cowan as an appendix to his paper.]

\section{Henley, September, 1848.}

My dear Sir,-Agreeably to your request, I have committed to paper a brief account of the inroad of cholera into this neighbourhood in 1832. The singular progress of this scourge from India to Europe on a former occasion, when, after ravaging Jessore in 1818, it attacked the crew of the Warren Hastings and other East Indian vessels in the Bay of Bengal. Spreading over China, after reaching Canton in October, 1820, it extended itself through Persia in 1823, re-appearing in the autumn for several successive years in the same localities. In the spring of $\mathbf{1 8 3 0}$ it showed itself for the second time in Astracan, diffused itself over Russia, reaching Moscow in September, Warsaw in April, 1831, and subsequently Archangel, Riga, and this country in 1832. The similarity of its present course has arrested the attention of medical men, and made them anxious to be prepared to meet this formidable disease with the most active and efficient remedies. I am not aware that $I$ can add anything new in the treatment of this malady, but having attended forty-one cases, I most willingly give the result of my own experience.

In September, 1832, I was called to attend several severe cases of diarrhcea, putting on the well-known symptoms of cholera, attended with severe vomiting and purging of rice-water or "congee" stools, violent cramps in the legs, weak and irregular pulse, blue appearance of the nails and lips, livid hue of the body, corrugated skin of the bands, suppression of urive, impatience of being covered up by the bedclothes, although the skin was cold, and the bodycovered with a clammy moisture, these symptoms proving rapidly fatal within twenty-four hours, unless speedily relieved by the most actire treatment.

The first case occurred in Henley on the 9th of September, in the lowest and dampest part of the town, and proved fatal in twenty-four hours. Six days elapsed before another case occurred, but on the ten following days, fourteen persons living in the same locality were seized with it, four of whom died. In October there were only two cases, one of which proved fatal. On the 3rd of November it re-appeared with additional violence in the upper and high part of the town, but from the experience $I$ had had in the treatment of the former cases, few now proved fatal. The last case was registered on the 12th of December, when the disease took its departure from Henley.

In all, forty-one persons were attacked, eight of whom perished, and five of these fatal cases occurred amongst those that were first attacked, and they had been treated with stimulants,-brandy, æther, ammonia, and calomel and opium. Finding this plan did not succeed so well as I could wish, I treated my subsequent patients, when called in at the commencement of the attack, and the case admitted of it, with one full bleeding, and administered an emetic, with ipecacuanha and calomel, and gave calomel and opinm every hour after, with as much cold water as the person desired to drink, and afterwards supported the strength of the patient with broth, gruel, wine, \&c. I will report one case to illustrate my plan of treatment.

Ann Martin, aged 14, a delicate girl, was seized at two o'clock a.m., (the usual period of attack,) on the 9 th of November, with the symptoms of cholera. She took a full dose of ipecacuanha and calomel directly, then calomel and opium every hour after, and as she complained of great thirst and burning heat at the epigastrium, I ordered a bucket of cold water to be placed by her bed-side, and she was desired to drink as much as she pleased. Every ten to twenty minutes she called for half a pint of cold water, drank it hastily, and lay down quiet for a short time, but as soon as it became warm in her stomach, she vomited it up with violence, in fact spouting it half across the bed-room; she immediately would call for more cold water, which always afforded her relief, this being in a short time ejected in a similar manner. During the first twelve hours she drank between two and three gallons, the second night not a quart, and she afterwards gradually recovered from the subsequent ferer with salines and a nourishing diet. The great prostration of strength that follows these attacks requires great attention to diet, and to avoid exposure to cold, to prevent relapses.

I will conclude by relating a case of cholera arising from breathing foul air, which may help to throw some light on the origin and causes of this mysterious and singular disease.

Mr. Knight, of Nettlebed, aged 35, a mason by trade, previously healthy, was employed to clean out the mud and sediment of a rain-water tank; this was done without any previous ventilation, and occupied him several hours. Whilst at work he did not observe any very offensive effluvia. This was on Tuesday, the 13th of June, 1837. Two days afterwards, on Thursday the 15 th, I was sent for to see him at 6, a.m.; he had been seized during the night with romiting and purging, violent cramps, and all the symptoms of cholera. He was bled, took calomel and opium every hour, with salines, had mustard sinapisms applied to the abdomen, and warm frictions orer the body, but he died the next day before two o'clock, thirty hours after I first saw him, and seventy-six after inhaling the foul air of the tank. His own expression was, " that his blood was poisoned." 
The similarity of the symptoms to $\mathrm{my}$ former cases of cholera forcibly struck me at the time, and led me to suppose that inhaling the exhalations of the many stagnant pools and decaying vegetable matter in the old water-tanks of India, was very frequently the cause of cholera in the low swampy districts of that country. Apologising for this basty sketch,

I remain, my dear Sir,

Yours very truly,

T. W. JESTON.

\section{CASE OF PURPURA HAMORRHAGICA.}

By E. T. Roe, M.D., Plymouth.

Maria B., housemaid, aged 30 , of healthy appearance, slightly above the middle height, of fair complexion, brown hair and eyes, osseous system largely developed, the bones of the hand especially being unusually large for a female, eren in her station.

She states that she is a twin, that her father and mother are living and well, and that all her family, consistlng of one sister and six brothers, are strong and robust. Her state of health has been generally good, but she has suffered occasionally from a feeling of sinking at the pit of the stomach, and from flatulence and sick headache. She only recollects having had one serious illness in her life, and that was a fever, many years ago.

Six weeks before her present attack, she observed a blackness around one knee, and she suffered also from a severe " cold on the chest." The discoloration continued for a fortnight, and was ascribed to kneeling.

On the evening of the 27 th of June she retired to bed as well as usual, and slept soundly. On rising the following morning, she observed some bruises and marks in the right infra-clavicular region, which she showed to her mistress, laughingly remarking that her fellow servant had pinched and treated her very badly during the night. She felt well, but was very properly ordered to obtain medical advice, and on my seeing her she presented the following appearances:-

An ecchymosis under the right clavicle of about an inch square, surrounded by a few petechiæ; no spots elsewhere, except inside the lower lip. She is cheerful, and says there is nothing the matter with her. Pulse 100 , soft, and presenting no peculiar feature; heart's impulse powerful; sounds normal. Says she bass always had palpitation, but never been prevented doing her work by it. Urine natural; bowels regular; motions healthy. She has taken nothing unusual to eat, and the most searching enquiry fails to detect any cause for the onset of the malady.

I ordered her a turpentine mixture, and a smart purgative. Lemonade as ordinary drink.

29th. The ecchymosis on the right side the same as yesterday, but petechiæ have appeared on the left and over the legs and trunk; none on the arms. Blood oozes from the inner part of the lower lip. She wat sent to bed and ordered a mixture consisting of Dec. Matico, Potassæ Chloras, and Ol. Terebinth., every two hours.

30th. The bleeding continues from the lower lip, and this morning has commenced to issue from the left nostril. The whole body is covered with ecchymoses, petechiæ, and vibices; the most extensive extravasations being on the lower jaw, and on the inner part of the left thigh immediately above the knee. She is in no pain, appears cheerful, and desires to be allowed to get up, as she thinks she shall soon be well again. Pulse 110, jerking; tongue slightly coated and reddened by the blood which has passed down ber throat; urine dark and evidently contained blood; motions black, grumous, resembling coffee grounds, but more fluid.

I plugged the nose with matico and ordered lemonade to be taken in large quantity. To be allowed wine, beef-tea, and oranges, and to continue the same medicine.

July 1st, 8 a.m. Decidedly worse, countenance exsanguined, features pinched and anxious; pulse 120, feeble and jerking; slight cough; tongue thickly coated, dark. The hæmorrhage from the nose is profuse, and large quantities of blood have from time to time been swallowed, which now makes her feel sick; she vomited several times and brought up much blackish blood; the lips are bleeding; the urine is of inky blackness; and throws down a heary black deposit on standing; the evacuations from the bowels are black fluid blood, without smell or any other evidence of containing fæculent matter. More petechiæ have made their appearance over the body.

I plugged the nostrils with matico, and ordered ammonia and catechu.

1 p.m. Worse; features pinched; eyes half closed; jactitation ; frequent sighing; deadly faintness ; surface of body cold and clammy; tongue thickly coated, black, and would be dry but that she is obliged constantly to wash her mouth out, to discharge the clots at the back of the pharynx. On looking into the mouth, the blood could be seen passing steadily down the cesophagus. Pulse 140 to 150 , reduced to a thread. She has lost all hope. Death, indeed, appeared inevitable, and an hour or two at the farthest would propably close the terrible scene-a scene which certainly presented as frightful characters as $I$ ever witnessed even in the worst form of Asiatic cholera. The bleeding lips and nose, the shrunken discoloured face, the bruised jaw, the frightfully black excretions, and blood on everything around, looked more like some horrible domestic tragedy than the work of a few brief hours of ravaging disease.

I determined to plug the nostril from behind, by passing a dosssil of lint through the posterior nares, and even while performing this trifling operation, I feared she would die. The tongue and pharynx were cold. Having succeeded in passing the plug through the left nostril, I ordered her a wine-glassful of brandy and the following mixture :-

R. Acidi Gallici, dr. ss. ; Tinct. Opii, m. iv., Aquæ, oz. ss., every half hour,-and plugged the right nostril, which, previously to the left having been stopped had not bled much, but from which the blood now flowed in a stream.

9 p.m. Slightly improved; bleeding ceased.

2nd, 5. a.m. No return of the external bleeding. 